Canadian Journal of Fisheries and Aquatic Sciences

Canadian Science Publishing Journal canadien des sciences halieutiques et aquatiques

\title{
Estimating consumption rate of Atlantic Salmon smolts (Salmo salar) by Striped Bass (Morone saxatilis) in the Miramichi River estuary using acoustic telemetry
}

\begin{tabular}{|r|l|}
\hline Journal: & Canadian Journal of Fisheries and Aquatic Sciences \\
\hline Manuscript ID & cjfas-2017-0373.R1 \\
\hline Manuscript Type: & Article \\
\hline Date Submitted by the Author: & 11 -Dec-2017 \\
\hline $\begin{array}{r}\text { Complete List of Authors: } \\
\text { Is the invited manuscript for } \\
\text { consideration in Special } \\
\text { Issue? : }\end{array}$ & $\begin{array}{l}\text { Daniels, Jason; Atlantic Salmon Federation, Research \& Environment } \\
\text { Chaput, Gérald; Fisheries and Oceans Canada Gulf Region }\end{array}$ \\
\hline Keyword: & $\begin{array}{l}\text { Atlantic salmon, Striped bass, random forest classification, SPATIAL } \\
\text { ANALYSIS < General, PREDATOR-PREY INTERACTION < General }\end{array}$ \\
\hline & \multicolumn{2}{|c|}{ Atlantic Salmon Federation, Research \& Environment } \\
\hline
\end{tabular}


1 Estimating consumption rate of Atlantic Salmon smolts (Salmo salar) by Striped Bass (Morone saxatilis)

2 in the Miramichi River estuary using acoustic telemetry

3 Jason Daniels, Gérald Chaput and Jonathan Carr

4 Jason M. Daniels and Jonathan Carr. Atlantic Salmon Federation, 15 Rankine Mill Road, Chamcook, NB, 5 Canada, E5B 3A9

6 Gérald Chaput. Fisheries and Oceans Canada, 343 University Avenue, Moncton, NB, Canada, E1C 5K4

7 Corresponding author: Jason M. Daniels (email: jdaniels@asf.ca, phone: (506) 529-1039) 


\section{Abstract}

Differentiating detections of a telemetered fish from those of predators which may have consumed that telemetered fish presents problems and opportunities. Previous efforts to quantitatively

12 classify predation events have had to rely on data from unknown states of fish (i.e. unsupervised 13 learning techniques) with the consequence that model performance cannot be refined or compared to 14 alternate models. We circumvent this limitation by analysing acoustic telemetry track data to 15 differentiate movement patterns of tagged Striped Bass (Morone saxitilis) from those of Atlantic Salmon 16 (Salmo salar) smolts which were known to not have been predated by Striped Bass over a three year 17 period in the Miramichi River estuary. A random forests classification model (i.e. supervised learning 18 technique) was used to differentiate the movement patterns of these two species and the model was 19 applied to Atlantic Salmon smolt movement characteristics to provide an index of Striped Bass 20 predation-derived mortality. The optimized random forests model inferred that predation rates by 21 Striped Bass were highly variable between years for two smolt stocks, ranging from $1.9 \%$ to $17.5 \%$. 22 Spatial and temporal overlap of the two species is a likely factor defining the between stock and annual 23 variation of predation rate estimates. 


\section{Introduction}

Telemetry studies often assume that detections are from the individual tagged. This assumption is violated when a tagged fish is consumed by a predator or scavenger and the tag continues to be detected by acoustic receivers (Gibson et al. 2015). Miniaturization of acoustic transmitters is permitting researchers to make inferences on survival and movement behaviour of increasingly smaller fish (Welch et al., 2009), exasperating the issue of predation in telemetry studies. Biases in movement behaviour and survival can be introduced if no attempt is made to differentiate between the detections of targeted species of interest and those of possible predators. As acoustic telemetry became a more widely adopted tracking method, classification of movement behaviours of presumed predated and presumed unpredated fish evolved from observations (Beland et al. 2001), subjective and qualitative analyses (Melnychuk et al. 2013) and, more recently, to quantitative approaches (Gibson et al. 2015; Romine et al. 2014). Efforts to quantify predation events, however, have had to rely on data from unknown states of fish otherwise termed unsupervised classification methodologies. This has primarily been due to the absence of known states of the tagged individuals as either having been predated or not.

In the absence of data of known states of tagged individuals, model classification error cannot be evaluated. Furthering the development of quantitative models, especially those capable of being evaluated, presents several important implications: (1) they allow for the evaluation of model performance and therefore competition between models, (2) they allow repeatable identification of

42 predated individuals and removal of their biased detection, and (3) they provide researchers with an opportunity to study the impacts and extent of predation. Here we seek to build upon previous work by

45 Salmon smolts (Salmo salar) that may have been consumed by Striped Bass (Morone saxatilis) in the mortality on salmon smolts. 
Striped Bass are found in estuaries and near-shore coastal waters along the eastern seaboard of

North America. A distinct population in the southern Gulf of St. Lawrence (SGoSL) is considered to be the northern limit of the species range (Bradford and Chaput 1996). This population is broadly distributed and contained to the southern Gulf of St. Lawrence between the eastern tip of the Gaspe

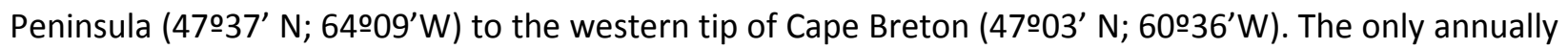
predictable spawning location of this population is in the Northwest Miramichi River (46.57' N; $\left.65040^{\prime} \mathrm{W}\right)$. The abundance of spawners was at a very low point in the mid 1990s, with historical variations in abundance and declines largely attributed to fisheries (Bradford and Chaput 1996). Incremental management measures led to the closure of commercial and recreational fisheries from 1996 to 2000 (DFO 2014). Following the implementation of these management actions, the abundance of SGoSL Striped Bass on the spawning grounds increased from fewer than 5,000 fish in the mid-1990s to an estimated 318,000 fish in 2016 (DFO 2017). The Miramichi River estuary and bay is a well-known overwintering site for Striped Bass (Douglas et al., 2006; DFO 2014). Striped Bass spawn in the upper reaches of the Northwest Miramichi River estuary during late May and June (Douglas et al. 2006, 2009). The Miramichi River also supports one of the largest runs of Atlantic Salmon in North America however the abundance of Atlantic Salmon in this river has declined over the past two decades much like Atlantic Salmon throughout the North Atlantic (Chaput 2012). Estuaries are considered to be areas with high mortality for salmon smolts due to the physiological stress associated with migration, anthropogenic stressors, and predation (Thorstad et al. 2012). Telemetry studies of Atlantic Salmon smolts have estimated a two-fold decline in apparent survival rates in the Miramichi estuary from the mid 2000s to recent years (2013-2016) but not in a neighbouring group of rivers in the SGoSL (Chaput, G., Daniels, J., Carr, J., Jonsen, I., and Whoriskey, F. In review). The decline in apparent survival rates of acoustically tracked salmon smolts in the Miramichi estuary has occurred concurrently with the recent large increases in Striped Bass spawner abundances in that area. The spawning aggregation of Striped 
72 Bass overlaps spatially and temporally with the seaward migration of Atlantic Salmon smolts from the

73 Miramichi River. Predation of Atlantic Salmon smolts by Striped Bass over a very narrow window of time 74 corresponding to the migration period of salmon smolts has been confirmed from diet studies of Striped

75 Bass in the Miramichi River area (DFO 2016).

While the increased abundance of Striped Bass in the SGoSL is unlikely to be the only factor

77 contributing to the multidecadal decline of Atlantic Salmon in the Miramichi River and throughout eastern Canada, the extent of the inter-species interactions and their consequences during the initial 79 migration period are poorly understood. In this study, we model differences in movement 80 characteristics of Atlantic Salmon smolts and Striped Bass spawners using acoustic tag detections to 81 estimate the proportions of tagged Atlantic Salmon smolts that may have consumed by Striped Bass. We 82 compiled a data set consisting of 'true' smolt and 'true' Striped Bass movement behaviours to first train 83 a random forests model (a supervised classification technique; Breiman 2001), to differentiate between 84 the two species' movement characteristics. The objective of this study was to apply the model 85 predictions to movement patterns of acoustically tagged smolts to determine which Atlantic Salmon 86 smolt patterns whose true state was not known had acoustic tracks which were more similar to those of 87 Striped Bass and thus could be interpreted as a probable predation event. Using the classification model, 88 estimates of the proportion of acoustically tagged Atlantic Salmon smolts presumably consumed by 89 Striped Bass in the Miramichi River are estimated annually from 2013 to 2016. To confirm the extent of 90 the spatial and temporal overlap between tagged Striped Bass and tagged Atlantic Salmon smolts in the 91 Miramichi estuary, we present an estimate of the percentage overlap between the two species. 


\section{METHODS}

\section{Field study}

\section{Description of the Miramichi river system}

The Miramichi River system has a catchment area of roughly $14,000 \mathrm{~km}^{2}$ (Fig. 1). There are two main branches of the Miramichi River; the Northwest Miramichi River (NW) and the Southwest Miramichi River (SW) which both drain into a single estuary that enters the SGoSL at latitude $47^{\circ} \mathrm{N}$ (DFO 2013). The Southwest Miramichi River is the larger of the two branches with over double the mean yearly discharge (177 and $86 \mathrm{~m}^{3} \mathrm{~s}^{-1}$ comparatively). The lower portions of both branches are under tidal influence.

\section{Description of the tagging protocols}

\section{Atlantic Salmon smolts}

Two stocks of Atlantic Salmon smolts were collected using rotary screw traps, located at Rocky Brook Salmon Camp for the SW (46.600481N, 66.632079 W) and at the NW $\left(47.094277^{\circ} \mathrm{N}\right.$, 65.837024 oW) (Fig. 1). Smolts $\geq 13 \mathrm{~cm}$ fork length were preferentially selected to accommodate the acoustic transmitter. Vemco V9-6L acoustic transmitters ( $9 \mathrm{~mm}$ diameter by $21 \mathrm{~mm}$ length, $2.9 \mathrm{~g}$ in air) were used in 2013 and 2014. We began to transition to smaller V8-4L (8 mm diameter by $21 \mathrm{~mm}$ length, $2 \mathrm{~g}$ in air) acoustic transmitters in 2014 and they were used exclusively in 2015 and 2016. In all years, acoustic transmitters were uniquely coded and programmed to emit signals at random time intervals between $25 \mathrm{~s}$ and $55 \mathrm{~s}$ at a frequency of $69 \mathrm{kHz}$. Before each surgery tag activation was confirmed with a Vemco VR100 mobile acoustic receiver (Amirix/Vemco, Bedford, Nova Scotia, Canada).

All smolts selected for surgery were held in in-stream tanks for 20 to 24 hours to allow for digestion of stomach contents. At the SW, smolts were released approximately $100 \mathrm{~m}$ downstream of the screw trap at the confluence of the SW Miramichi and Rocky Brook. At the NW, smolts selected for 
115 surgery were transported in an oxygenated $1 \mathrm{~m}^{3}$ insulated HDPE tank. The surgery and release location $116(47.1872249 \mathrm{~N}, 65.89506 \mathrm{~N})$ was located approximately $13 \mathrm{~km}$ upstream from the rotary screw trap.

Smolts were anaesthetised using clove oil $\left(0.2 \mathrm{ml} \mathrm{L}^{-1}\right.$ concentration) until loss of equilibrium and

118 very little gill movement (generally 3-5 minutes). Once this had occurred, fork length (cm) was taken 119 before the fish was placed ventral side up on a v-shaped operating board lined with a chamois leather.

120 All surgical tools and tags were disinfected in anhydrous ethyl alcohol prior to each surgery, before

121 being rinsed in distilled water. An approximately $11 \mathrm{~mm}$ incision was made along the mid-ventral line 122 about $20 \mathrm{~mm}$ anterior to the pelvic girdle. Acoustic transmitters were inserted via the incision into the 123 abdominal cavity of the fish. The fish's gills were continuously irrigated with a wash bottle containing 124 anaesthetic during the surgery. The fish's body was kept moist throughout the surgery by using a wash 125 bottle containing river water to irrigate the skin, avoiding the incision area. Incisions were sealed using 2 126 to 3 interrupted stitches using 4/0 non-absorbable black monofilament nylon sutures with $19 \mathrm{~mm}$ 127 reverse cutting blades. Fish were placed in an aerated recovery bath for observation. Once equilibrium 128 had been restored, fish were transferred to in-river holding tanks at the respective release sites, and 129 held for a minimum of one hour before release.

During 2013 to 2016, a total of 514 Atlantic Salmon smolts were acoustically tagged and released

131 in the Miramichi River (Table 1). Of these, 374 smolts were subsequently detected between head of tide 132 receivers and Miramichi Bay exit receivers. The mean fork length of smolts selected for acoustic tags 133 was $14.2 \mathrm{~cm}$ within a range of $12.1 \mathrm{~cm}$ to $18.2 \mathrm{~cm}$ (Table 1). Surgery/release dates ranged between May 13410 and May 30 with a mean surgery/release date of May 21 over all years. Striped Bass In October 2013, a total of 40 Striped Bass were selected from catches at the Department of 137 Fisheries and Oceans Canada (DFO) index estuary trapnet in the Southwest Miramichi River (46.600481 oN, 66.632079W). Details of the trapnet operation are given in Hayward et al. (2014). The Striped Bass 
tagged in 2013 were collected between October 10 and 21. The tagged bass had a mean fork length of $58.8 \mathrm{~cm}$, with a range of 45.6 to $73.5 \mathrm{~cm}$. The acoustic tags used were a combination of Vemco V16T-4L and V16TP-4L configured with a random ping interval between 60 and 180 seconds. Striped Bass from

142 the daily catches were retained in the trapnet holding area, and transferred to shore in small numbers

143 for tagging. Tagging and handling procedures were as described by Douglas et al. (2009). Some of these tagged bass overwintered in the tidal waters of the Miramichi River and were tracked in the spring onto the spawning grounds until they left the area. A large number of these fish returned in subsequent fall months of 2014 and 2015 to overwinter and participated in spawning during the springs of 2014 to 2016

147 (DFO 2015, 2016).

In late summer 2013, the Ministère des Forêts, de la Faune et des Parcs, province of Quebec, acoutically tagged Striped Bass captured along the north shore of Chaleur Bay to determine the movements of Striped Bass at the northwest extent of the defined geographic distribution of the southern Gulf of St. Lawrence population. Striped Bass were collected by angling. A total of 50 bass were sampled and tagged with Vemco V13 acoustic transmitters configured with a random ping interval

153 between 60 and 180 seconds. Tagging and handling methods were consistent with DFO methodology.

154 Of the bass acoustically tagged in this area, 38 were detected in tidal waters of the Miramichi River prewinter 2013 to 2016.

Description of the receiver deployment: deployed within the Miramichi river system and Gulf of St Lawrence to record smolt passage (Fig. 1). For 159 this study, 7 receivers were moored in the NW, 5 in the SW, and 5 in the mainstem Miramichi. The outer bay array (where Miramichi Bay joins the Gulf of St Lawrence) consisted of 11 receivers and the Strait of

161 Belle Isle (SoBI) array consisted of 24 receivers. All receivers were deployed in consistent locations 162 between 2013 and 2016 apart from an additional 28 receivers deployed approximately $3.5 \mathrm{~km}$ north of 
163 the SoBI array in 2015 and 2016 to assess the detection efficiency of the SoBI array (Fig. 1). All receivers 164 were attached to moorings consisting of varying weight anchors (depending on current and possible 165 surface conditions), line and surface floats. In shallow reaches of the NW and SW, receivers were 166 attached approximately $1 \mathrm{~m}$ below the surface floats whereas moorings in deeper water had receivers 167 attached approximately $4 \mathrm{~m}$ below the surface floats. Sinking line was used from the surface floats to a 168 169 nylon swivel located below the receiver, which in turn was attached to the anchor with floating line.

\section{Statistical analyses}

\section{Behavioural classification}

The movement patterns of Striped Bass were described directly from the tracking data as there is no reason to believe that a tag originally placed in a Striped Bass would have ended up in another fish species as there are no known fish predators of sufficient size in the Miramichi that could consume the

174 Striped Bass tagged in this study.

175 We assumed that tags originally placed in Atlantic Salmon smolts that were subsequently detected at the Strait of Belle Isle array arrived there in post-smolts and not in any other aquatic species. As such the movement patterns of these Atlantic Salmon smolts were considered to be those of 'true'

178 tagged Atlantic Salmon smolts which had not been predated upon by Striped Bass or any other fish 179 predator.

In three of four years, detection data from concurrent Striped Bass and smolt migration studies

181 were acquired. Movement patterns of 'true' smolts were described from the smolt tagging experiments 182 of 2013 to 2016 . The movement patterns of Striped Bass were described from the tracking data during 1832014 to 2016. Detections of Striped Bass and Atlantic Salmon smolts were recorded on the common 184 acoustic receiver deployments with the study period for each year (i.e period between the first and last 185 detection of any smolt transmitter in the Miramichi River). 
Eight variables characterizing movement patterns were generated based on similar criteria to

187 those of Gibson et al. (2015). These variables included: (1) average speed through system, (2) time between first and last detection within the study period, (3) count of switches in upstream and downstream movement direction, (4) cumulative upstream distance between receiver detections, (5) cumulative distance between receiver detections, (6) time on defined bass spawning grounds (between the 57 and 69 kilometer mark on the Northwest Miramichi River), (7) time between first and last detection on defined bass spawning grounds, and (8) count of visits and switches between the Northwest and Southwest Miramichi Rivers. These variables adequately differentiated the two species movement patterns based on descriptions of Douglas et al. (2009) and Kocik et al. (2009). transmitters were continuously detected at a single receiver over an extended period of time (i.e. the transmitter stops moving). This is likely due to the mortality of a tagged fish or tag expulsion within the detectable range of the receiver.

Random forests (RF) models to differentiate between the two species' movement patterns were constructed (see Cutler et al. 2007 for random forest description) using the "randomForest" package 202 (Liaw and Wiener 2002) in program R (R Core Team). Inferences of the proportions of acoustically 203 tagged Atlantic Salmon smolts that had movement patterns characteristic of Striped Bass were obtained 204 as follows: (1) variables describing the movements of the two species were developed, (2) a dataset of 205 'true' salmon and bass was compiled to train the RF model to differentiate between smolt and bass 206 movements, (3) the inferences of the RF model were optimized by using k-fold cross validation to 207 choose a set of randomly selected predictors within each tree of the RF model, (4) the RF model 208 structure based on the training set was applied to all smolt detection data during the study period, to 209 estimate the probability of an individual smolt data track being either most similar to smolt behaviour or 
210 bass behaviour, and (5) by stock and year, the estimated percentages of tagged smolts exhibiting 211 probable Striped Bass movement patterns were compiled. Movement patterns of individuals from each species with known states were required to train the

213 RF model to differentiate between smolt-like and bass-like movements. To classify movement patterns

214 in a supervised method it was assumed that: (1) transmitters implanted in Striped Bass are 215 representative of 'true' Striped Bass movements and (2) transmitters implanted in Atlantic Salmon 216 smolts that were detected at the Strait of Belle Isle (SoBI) receiver gate are representative of 'true' smolt 217 movements within the Miramichi River. Detection data from both the SoBI and the Ocean Tracking 218 Networks' (OTN) Cabot arrays suggest that SoBI is the primary point of exit of salmon smolts from the 219 Gulf of St. Lawrence. The SoBI gate is located at the extreme northern limit of the GoSL, roughly $780 \mathrm{~km}$ 220 from the mouth of the Miramichi River (Fig. 1). Shultz et al. (2015) examined the evacuation rates of 221 acoustic tags from prey ingested by Striped Bass and reported a mean evacuation time of 1.8 days and a 222 negative association with temperature. Given that the SoBI receiver gate is well beyond the defined 223 known range of Striped Bass (DFO 2015) and the amount of time (30 to 61 days; Chaput, G., Daniels, J., 224 Carr, J., Jonsen, I., and Whoriskey, F. In review) an ingested acoustic tag would need to remain in the 225 gastrointestinal tract of a predator migrating to and detected at the Strait of Belle Isle, we believe our 226 second assumption to be robust.

\section{Model Optimization and Performance}

Within the randomForest function the number of randomly selected variables (i.e. mtry) used for each tree was optimized. We defined the potential number of variables equal to the total number of descriptive variables (8). To select the optimal number of variables, ten-fold cross validation was used to 231 resample the data, fit a model, and estimate the mean and 95\% confidence interval of the Kappa 232 statistic as per Kuhn and Johnson (2013). The Kappa statistic addresses the accuracy that would be 233 expected by chance (i.e. accounts for imbalance between classes) and takes values ranging from -1 to 1. 
234 Values of 1 indicate perfect agreement whereas a value of 0 represents agreement expected by chance 235 alone (Viera and Garrett 2005). Among candidate models with differing mtry values, the model with the optimal Kappa value was selected. The mtry value from this optimal model was then used to refit the 237 model using all data.

\section{Model Application}

For all acoustic transmitters implanted into smolts that also had detections (Table 1) within the study site, the optimal RF model was applied to generate the probability of each transmitter detection data exhibiting Striped Bass and smolt movement patterns (i.e. probabilities of both classes sum to one for each transmitter). Probabilities generated through the RF model reflect the proportion of trees within the forest with votes for the respective classes. A smolt track was assigned to smolt or bass categories using three approaches. First, a binary classification corresponding to a cut-off value of 0.5 with values $\leq 0.5$ being a smolt pattern and $>0.5$ being a bass pattern. Second, a scaled estimate, which is the sum of individual bass classification probabilities of each smolt tag divided by the total number of 247 smolt tags modelled. This scaled estimation accounts for uncertainty in the assignment to either classification. Third, we present a three-level classification where we chose an arbitrary probabilistic cutoff with values $\leq 0.20$ classified as a smolt pattern, $\geq 0.80$ classified as a bass pattern and probability predated by Striped Bass was the number of smolts assigned to the bass category divided the total of smolts with detections for each smolt stock and year.

\section{Spatial and temporal overlap}


distribution field were those inferred to exhibit smolt behaviours as defined from the binary 259 classification of the RF model. To calculate KUD overlap of NW smolts to those of Striped Bass, smolt and bass detections on the Northwest and mainstem Miramichi River receivers were used. The Southwest and mainstem Miramichi River receiver detections were used to calculate overlap of SW smolts and bass. Day of the year served as the temporal dimension in the analysis. Points within these two dimensions were estimated using each transmitter's mean upstream distance by day. KUDs were created using the "ks" package (Duong 2007) in program R (R Core Team). Bandwidth selection was performed using smoothed cross-validation. The percent of the area of each smolt KUDs occupied by the area of the corresponding bass KUDs, each truncated to the $95^{\text {th }}$ isopleth, was calculated for the years 2014 to 2016 (Cooper et al. 2014; Simpfendorfer et al. 2012).

\section{Results}

Movement patterns of tagged Atlantic Salmon smolts detected at SoBI and of tagged Striped Bass were pooled across all years to train the RF model. Detection data used to characterize Striped Bass

271 movements were assembled from a total of 228 bass; 66 bass in 2016, 80 bass in 2015, and 82 bass in

272 2014. Detection data of 'true' smolt movement patterns were compiled for 63 individuals; 16 smolts in

2732016,28 smolts in 2015, 12 smolts in 2014, and 7 smolts in 2013. A 'true' salmon smolt movement

274 pattern was typically characterized by unidirectional downstream movements (Fig. 2 a,b,c,d) and 'true'

275 Striped Bass movement patterns had more frequent up and downstream reversals (Fig. 2e). No Striped

276 Bass detection data were available for 2013, however we included smolt detection data from this year

277 because several smolts detected at the SoBI gate exhibited more variable in-river movement patterns in

278 that year compared to the other years (e.g. Fig. 2b). There was no evidence to suggest that Striped Bass

279 had annual variations in movement patterns. Inclusion of the 2013 smolt detection data allowed for a

280 greater range of 'true' smolt movement patterns to be included in the training data set to derive the

281 final and optimal classification model (Fig. 3). Due to an inconsistent number and deployment location 
282

283

284

285

286

287

288

289

290

291

292

293

294

295

296

297

298

299

300

301

302

303

304

305

of receivers in the Miramichi River system, no data are available prior to 2013 to train and/or apply predictions of the model.

Random forest models were trained across the range of eight potential variables and each RF model consisted of 10,000 trees. The optimal number of randomly selected variables selected for each tree in the random forest was five. This optimized model had a Kappa value of 0.989 (s.d. 0.036). The final model had a classification error of 0.0 for the Striped Bass classification and 0.016 for the smolt classification (one smolt was classified as having movement patterns most similar to Striped Bass). This high degree of classification accuracy on the training data was somewhat expected given the considerable differences between species for the movement variables used (Fig. 3).

Applying the optimized RF model to all smolts acoustically tagged and subsequently detected in the Miramichi estuary provided inferences on the proportions of tagged smolts which exhibited Striped Bass movement patterns. The distributions of these probabilities for each stock and year are presented in Figure 4. Given the generally bimodal distribution near 0 and 1 for these classification distributions, this approach demonstrates that the characterization of tagged smolt movements can be classified with a reasonable degree of certainty. The percentages of smolt tags predicted to have movement patterns in the Miramichi estuary that are characteristic of Striped Bass tags and by inference were consumed by bass (i.e. binary classification estimate) are presented for each stock and year of the study (Table 1). To account for any uncertainty in the classification both the scaled estimate and the percentages of smolt tags with a classification probability $\geq 0.80$ are also presented in Table 1 . Using the scaled estimate across all year's predictions (i.e. 2013 to 2016), tagged smolts from the NW were characterized more frequently as showing Striped Bass movement patterns (15.3\%) than tagged smolts from the SW (8.6\%). Defining states of smolt tags under the three-level classification scheme (i.e. smolt, unknown or bass) presents slightly lower estimates for 2013 and 2016, compared to estimates using the binary classification scheme. Perfect agreement between the binary and three-level classification schemes was 
present for 2014 and 2015. For most years and stocks, few tagged smolt movement patterns were defined as belonging to an unknown state, ranging from $2.0 \%$ to $8.3 \%$ for NW smolt tags and $0.0 \%$ to 10.7\% for SW smolt tags (Fig. 5).

The spatial and temporal overlap between Striped Bass and Atlantic Salmon smolts based on tag detections varied annually in the Miramichi estuary but it was estimated to be greater for Northwest smolts than for Southwest smolts (Fig. 6). Striped Bass congregated most densely in the NW estuary in all years (Fig. 6). In 2014 and 2015 Striped Bass congregated in the mainstem Miramichi before spawning and during the tagged smolt migration period, however, this was not apparent in 2016 (Fig. 6). Most tagged smolts passed through the Miramichi estuary over a two-week period, typically from last week of May to the first week of June (Fig. 6). The spatial and temporal overlap between SW Miramichi tagged Atlantic Salmon smolts and tagged Striped Bass ranged from $18.7 \%$ to $56 \%$ (Fig. 6), whereas the spatial and temporal overlap between NW Miramichi smolts and Striped Bass ranged from $45.3 \%$ to $70.7 \%$ (Fig. 6). Spatial and temporal overlap between Striped Bass and both smolt stocks was lowest in 2015.

\section{Discussion}

Two previous studies (Gibson et al. 2015; Romine et al. 2014) attempted to use quantifiable methods to estimate the number of consumption events using acoustic telemetry data and both studies considered salmonid and Striped Bass interactions. These studies were limited to unsupervised learning (i.e. clustering) algorithms (which hierarchically organize data based on similarity) because they had no information on movements of prey fish of known states. In both studies, it was assumed that Striped Bass movement patterns represented 'true' Striped Bass patterns and these were used to validate the clustering of Striped Bass. Romine et al. (2014), however, raised the issue of being unable to validate smolt classifications due to the infeasibility of recapturing smolts to confirm their true state (i.e. predated or not). Given that unsupervised techniques model the underlying structure of the data, model performance cannot be evaluated (i.e. classification error). This implies that the model generated 
cannot be refined or compared to alternate (i.e. competing) models to select an optimal classification model.

Here we circumvented this limitation by having data on potential predator movements and concurrent data on potential prey movement patterns that escaped predation and this information was used to guide a supervised learning technique, random forests. Many studies have outlined the enhanced prediction accuracy of supervised over unsupervised classification techniques (Guerra et al. 2011; Rozenstein and Karnieli 2011; Venkatesan and Kulkarni 2016). The training data set developed under these assumptions proved to be a near perfect classifier with one misclassification (a smolt classified as striped bass) of 63 'true' movement tracks (1.6\% misclassification rate).

While we have demonstrated that this methodology improves upon existing approaches to classify movement patterns, there are limitations. The presentation of the scaled consumption estimates provides an indication of the degree and direction of uncertainty in the estimated probability of smolt consumption events. In all but two cases (2013 SW smolts, 2016 NW smolts) the scaled estimate is greater than that of the binary output suggesting that the binary classification estimates may

344 underestimate potential predation events. Gibson et al. (2015) remarked, through a similar analysis, on 345 the limitations due to the quantification of movement characteristics across the extent of the study 346 period. The greater the amount of time a consumed smolt tag remains in a Striped Bass the more likely 347 the model is to identify the movement pattern as Striped Bass. On the other hand, smolt movement 348 patterns that deviate from the typical patterns of smolts detected at SoBI are also more likely to be assigned as Striped Bass consistent patterns, such as the example outlined in Figure $2 \mathrm{~b}$.

While this methodology could include multiple states if data were available (i.e. more than one 351 species of predator) the only potential predator fish species with tracking in this study was Striped Bass. 352 Misclassification of smolt movement patterns as Striped Bass (or any probabilistic weighting, with 353 respect to the scaled estimate) can occur if an alternate predatory species consumed a tagged smolt and 
presented movement patterns that more closely resembled those of Striped Bass. Misclassification due to alternate predators is most likely limited to that of piscine predators as avian or terrestrial predators would be expected to remove the transmitter from the study area and would no longer be detected by receivers, as was the case for some tags in the study. In the event an acoustically tagged smolt is consumed by a predator and few to no subsequent detections are made on receivers, the model classification would be to a smolt under the binary classification scheme. This is primarily due to movement characteristic measurements (exception of average speed between detections) being greater for Striped Bass than smolts in addition to the number of variables (5) included in each tree of the 362 forest.

To further address concerns with uncertainties in the smolt classifications we considered a threelevel classification system where smolt movement patterns with assignment probabilities between 0.2 and 0.8 we classified as 'unknown' states. Based on subjective review of the detection histories, smolt tags identified as exhibiting bass patterns under this three-level classification system (i.e $\geq 0.80$ probability) should be regarded as at or approaching the minimal level of consumption. This is expected as the 'unknown' state likely captures those consumed tagged smolts in which bass expelled the tags before the model could adequately respond to the behavioural change (i.e. model response time) in addition to possible intermediate smolt/bass movement behaviours (e.g. alternate piscine predators).

371 One half of the estimated striped bass predation from three-level classification scheme, agreed perfectly 372 with the binary classification scheme. This is indicative of the level of agreement between trees within 373 the RF model. The percent of 'unknown' tag classifications was generally greater for NW smolt tags 374 compared to the SW smolt tags (exception 2016). Given the higher degree of spatial and temporal 375 overlap for Striped Bass and NW smolts, model response time to predation events may account for the 376 greater percent of unknown classifications. To summarize, several factors can affect the probabilistic 377 assignment of the movement patterns of individual fish: the fish was not consumed by a predator but 
displayed a high level of in-river movement variability inconsistent with smolt or bass movement patterns; the tagged fish was consumed by a Striped Bass but there was an insufficient number of postpredation detections for the model to assign the movement pattern with a reasonable degree of certainty; the tagged smolt was consumed by an alternate predator with intermediate movement characteristics between smolts and bass; the tagged smolt died in the estuary for reasons other than predation after having moved or been displaced by currents before dropping out of the detection range of receivers; the tag was expelled by the smolt in the estuary.

Advances to address this question could be made using technologies that can define when and where consumption events occur. One such technology is predator tags which can signal consumption events based on a change in identification code triggered by the change in $\mathrm{pH}$ associated with the predator's gastrointestinal tract (Halfyard et al. 2017). This technology could define predation events more precisely than from movement pattern data as used in this study. Despite the ability of this technology to highlight consumption events at finer temporal and (potentially) spatial scales they are still not capable of fully defining when and/or where the predation event occurred because the triggering of the change in tag signal is subject to a time lag associated with consumption, digestion of the prey, and the switch in the identification code which would signal the consumption event.

Despite the method of interpreting the inferred percentage of smolts consumed by Striped Bass, the NW smolts were inferred to have been subjected to a greater than two-fold consumption rate in three of four years (exception 2013) relative to smolts from the SW. In addition, all three methods of interpretation display similar annual trends in consumption percentages. Note however that for the 2015 study year, the estimated Striped Bass spawner abundance in the Northwest Miramichi was the second highest of the assessed time series (301,000 spawners; DFO 2017), but the percentages of inferred tagged smolts consumed by Striped Bass was the lowest estimate for both stocks. This suggests that factors beyond Striped Bass abundance, such as spatial and temporal overlap of the two species in 
402 the estuary, may be important in defining smolt predation rates by Striped Bass. The timing of smolt 403 migrations and the location and timing of Striped Bass spawners on the staging and spawning grounds 404 are both largely conditioned on, but not limited to, similar temperature ranges (Chaput et al. 2002; 405 Douglas et al. 2009). Future research should focus on factors capable of predicting the degree of spatial 406 and temporal overlap between Striped Bass and both NW and SW Miramichi salmon smolts and how 407 this may be affected by variations in environmental conditions. predation event is to occur (Hebblewhite et al. 2005). Spatial and temporal overlap of the two species varied by year and stock in the Miramichi estuary. The variation of between stock spatial and temporal 411 overlap is consistent with the negligible time spent by tagged Striped Bass in the SW Miramichi (Douglas 412 et al. 2009). The estimated overlap between species occurred over a short duration, which is consistent 413 with the one to two week period when most smolts migrate through that zone and to the brief window 414 of time when Atlantic Salmon smolts were identified in Striped Bass stomach samples in the Miramichi 415 (DFO 2016). The higher inferred percentages of predation on NW smolts are consistent with the higher 416 estimated spatial and temporal overlap (2014 to 2016) between Striped Bass and salmon smolts in this 417 area.

The highest potential for overlap between SW tagged smolts and tagged bass was in the main 419 stem of the Miramichi and Miramichi Bay. The mainstem Miramichi estuary, below the confluence of 420 the NW and SW is a staging area where pre-spawning Striped Bass aggregate before moving upstream 421 onto the NW spawning grounds (Douglas et al. 2009; Douglas and Chaput 2011; DFO 2015). In 2015, 422 most tagged Striped Bass moved upstream to the NW spawning grounds before the SW tagged smolts 423 arrived at the main stem estuary (Fig. 6), and this corresponded with the lowest inferred consumption 424 rate (1.9\%) on SW tagged smolts during this study. 
There is a growing and expressed concern by the public regarding the perceived negative

426 consequences of a recovered and abundant Striped Bass population leading to a decline in abundance of

427 wild Atlantic Salmon in the Miramichi River. Over the four years of this study, the percentage of tagged

428 Atlantic Salmon smolts which were inferred to have been consumed by Striped Bass varied between $2 \%$

429 and $20 \%$. It is not clear what impact Striped Bass predation on smolts has on adult return rates and/or

430 population productivity as the vast majority of Atlantic Salmon smolts that migrate to sea do not survive

431 to return as adults (ICES 2017). Return rates of Atlantic Salmon smolts to adults in monitored multi-sea-

432 winter salmon populations of eastern Canada over the 2013 to 2015 smolt migration years ranged from

$0.3 \%$ to $10 \%$ (ICES 2017). Including mortality estimates from this study suggests the majority of mortality seemingly still occurs beyond the estuary. It is also not known the extent to which the mortality incurred in estuaries is additive, although it is unlikely to be so, nor how representative the inferences based on tagged Atlantic Salmon smolts are of movement patterns, vulnerability to, and ultimately predation of untagged and unmanipulated Atlantic Salmon smolts (Adams et al. 1998; Anglea et al. 2004). Studies as reported here and the longer term experiments to estimate the relative migration success of tagged Atlantic Salmon smolts in the Miramichi River and in neighbouring rivers without spawning Striped Bass populations (Chaput, G., Daniels, J., Carr, J., Jonsen, I., and Whoriskey, F. In review) provide important

441 information with which to address questions of predator/prey interactions of species of joint interest 442 and to support management interventions. The question of whether increased Striped Bass abundance 443 with associated biologically significant predation rates on migrating salmon smolts is the cause of 444 reduced abundance of anadromous Atlantic Salmon in the Miramichi may best be answered by 445 undertaking a large scale ecological experiment to reduce the abundance of Striped Bass in the 446 Miramichi River over a number of years and to quantify metrics of responses such as consumption rates 447 of tagged Atlantic Salmon smolts and the changes in abundance of adult wild Atlantic Salmon. While it is 
449 impact occurring within the river/estuary is far easier to address from the perspective of, but not limited 450 to, management resources and capabilities.

$451 \quad$ Acknowledgements

We acknowledge the Miramichi Salmon Association for their financial and technical support of

453 this research, with special thanks to Mark Hambrook and Holly Labadie for their contributions in the

454 field with smolt collection and tagging. The authors wish to thank Scott Douglas of Fisheries and Oceans

455 Canada and Valérie Bujold of the Ministère des Forêts, de la Faune et des Parcs of the province of

456 Quebec for their work and information regarding Gulf of St. Lawrence Striped Bass, which, allowed for

457 the production of this work. Thanks to Steve Sutton and Robert Otto of the Atlantic Salmon Federation

458 who provided helpful comments and edits of earlier manuscript versions. We are grateful to all financial

459 contributions to this program: Supporters of the Adopt a Smolt program, International Paper

460 Foundation, Amirix Systems Inc., Echo Foundation, R. Howard Webster Foundation, John and Judy Bragg

461 Family Foundation, RBC Blue Water Fund, The Moore Charitable Foundation, Joseph and Joan Cullman

462 Conservation Foundation, The Atlantic Salmon Conservation Foundation, and the New Brunswick

463 Wildlife Trust Fund. 


\section{References}

Adams, N., Rondorf, D., Evans, S., Kelly, J., and Perry, R. 1998. Effects of surgically and gastrically implanted radio transmitters on swimming performance and predator avoidance of juvenile Chinook salmon (Oncorhynchus tshawytscha). Can. J. Fish. Aquat. Sci. 55(4):781-787

Anglea, S., Geist, D., Brown, R., Deters, K., and McDonald, R. 2004. Effects of acoustic transmitters on swimming performance and predator avoidance of juvenile Chinook salmon. N. Am. J. Fish. Manage. 24(1):162-170

Beland, K.F., Kocik, J.F., vandeSande, J., and Sheehan, T.F. 2001. Striped bass predation upon Atlantic salmon smolts in Maine. Northeast. Nat. 8(3): 267-274. doi:10.2307/3858483

Bradford, R.G., and Chaput, G. 1996. The status of striped bass (Morone saxatilis) in the southern Gulf of St. Lawrence in 1995. DFO Atl. Fish. Res. Doc. 96/62 [online]. Available from http://www.dfompo.gc.ca/CSAS/Csas/DocREC/1996/1996_062_f.pdf

Breiman, L. 2001. Random Forests. Machine Learning, 45(1): 5-32. https://doi.org/10.1023/A:1010933404324

Chaput, G. 2012. Overview of the status of Atlantic salmon (Salmo salar) in the North Atlantic and trends in marine mortality. ICES J. Mar. Sci. 69: 1538-1548.

Chaput, G., Hardie, P., Hayward, J., Moore, d., Shaesgreen, J., and NSPA. 2002. Migrations and biological characteristics of Atlantic salmon (Salmo salar) smolts from the Northwest Miramichi River, 1998 to 2000. Can. Tech. Rep. Fish. Aquat. Sci. No. 2415. 70p.

Cooper, N.W., Sherry, T.W., and Marra, P.P. 2014. Modeling three-dimensional space use and overlap in birds. The Auk 131(4): 681-693.

Cutler, D.R., Edwards, T.C., Beard, K.H., Cutler, A., Hess, K.T., Gibson, J., and Lawler, J.J. 2007. Random Forests for Classification in Ecology. Ecology 88(11): 2783-2792. 
487 488 489 490 491 492 493 494 495 496 497 498 499 500 501 502 503 504 505 506 507 508 509 510

DFO. 2001. Striped bass (Morone saxatilis) southern Gulf of St. Lawrence. DFO Science Stock Status Report D3-15 [online]. Fisheries and Oceans Canada. Available from http://www.dfompo.gc.ca/csas/Csas/status/1997/D3-15e.pdf

DFO. 2007. Recovery potential assessment for the St. Lawrence estuary, southern Gulf of St. Lawrence and Bay of Fundy striped bass (Morone saxatilis) populations. DFO Can. Sci. Advis. Sec. Sci. Advis. Rep. 2006/053 [online]. Fisheries and Oceans Canada. Available from http://wavesvagues.dfo-mpo.gc.ca/Library/328105.pdf

DFO. 2013. Atlantic salmon (Salmo salar) returns to the Miramichi River (NB) for 2012. DFO Can. Sci. Advis. Sec. Sci. Resp. 2013/009 [online]. Fisheries and Oceans Canada. Available from http://publications.gc.ca/collections/collection_2013/mpo-dfo/Fs70-7-2013-9-eng.pdf

DFO. 2015. Recreational fishery catches, spawner abundance, and biological characteristics of striped bass (Morone saxatilis) in the southern Gulf of St. Lawrence in 2014. DFO Can. Sci. Advis. Sec. Sci. Resp. 2015/011 [online]. Fisheries and Oceans Canada. Available from http://publications.gc.ca/collections/collection_2015/mpo-dfo/Fs70-7-2015-011-eng.pdf

DFO. 2016. Spawner abundance and biological characteristics of striped bass (Morone saxatilis) in the southern Gulf of St. Lawrence in 2015. DFO Can. Sci. Advis. Sec. Sci. Resp. 2016/017 [online]. Fisheries and Oceans Canada. Available from http://publications.gc.ca/collections/collection_2016/mpo-dfo/Fs70-7-2016-017-eng.pdf

DFO. 2017. Spawner abundance and biological characteristics of Striped Bass (Morone saxatilis) in the southern Gulf of St. Lawrence in 2016. DFO Can. Sci. Advis. Sec. Sci. Resp. 2017/012 [online]. Fisheries and Oceans Canada. Available from http://www.dfo-mpo.gc.ca/csassccs/Publications/ScR-RS/2017/2017_012-eng.pdf pdf

Douglas, S.G., and Chaput, G. 2011. Assessment and status of striped bass (Morone saxatilis) in the Southern Gulf of St. Lawrence, 2006 to 2010. DFO Can. Sci. Advis. Sec. Res. Doc. 2011/097 
[online]. Available from http://publications.gc.ca/collections/collection_2013/mpo-dfo/Fs70-52011-097-eng.pdf

Douglas, S.G., Chaput, G., and Caissie, D. 2006. Assessment of status and recovery potential for striped bass (Morone saxatilis) in the southern Gulf of St. Lawrence. DFO Can. Sci. Advis. Sec. Res. Doc. 2006/041 [online]. Available from http://www.dfo-mpo.gc.ca/csas-sccs/Publications/ResDocsDocRech/2006/RES2006_041_e.pdf

Douglas, S.G., Chaput, G., Hayward, J., and Sheasgreen, J. 2009. Prespawning, spawning, and postspawning behavior of striped bass in the Miramichi River. Trans. Am. Fish. Soc. 138(1): 121134.

Duong, T. 2007. ks: kernel density estimation and kernel discriminant analysis for multivariate data in R. J. Stat. Softw. 21(7).

Gibson, A.J.F., Halfyard, E.A., Bradford, R.G., Stokesbury, M.J.W., Redden, A.M., and Jech, J.M. 2015. Effects of predation on telemetry-based survival estimates: insights from a study on endangered Atlantic salmon smolts. Can. J. Fish. Aquat. Sci. 72(5): 728-741. doi:10.1139/cjfas-2014-0245

Guerra, L., McGarry, L.M., Robles, V., Bielza, C., Larrañaga, P., and Yuste, R. 2011. Comparison between supervised and unsupervised classifications of neuronal cell types: a case study. Devel. Neurobiol. 71(1): 71-82. doi:10.1002/dneu.20809

Halfyard, E.A., Webber, D., Del Papa, J., Leadley, T., Kessel, S.T., Colborne, S.F., and Fisk, A.T. 2017. Evaluation of an acoustic telemetry transmitter designed to identify predation events. Methods. Ecol. Evo. doi:10.1111/2041-210X.12726

Hebblewhite, M., Merrill, E.H., and McDonald, T.L. 2005. Spatial decomposition of predation risk using resource selection functions: an example in a wolf-elk predator-prey system. Oikos 111(1): 101111. doi.org/10.1111/j.0030-1299.2005.13858.x 
534

535

536

537

538

539

540

541

542

543

544

545

546

547

548

549

550

551

552

553

554

555

556

557

ICES. 2017. Report of the Working Group on North Atlantic Salmon (WGNAS), 29 March-7 April 2017, Copenhagen, Denmark. ICES CM 2017/ACOM:20. 296 pp

Kocik, J., Hawkes, J., Sheehan, T., and F Beland, K. 2009. Assessing estuarine and coastal migration and survival of wild Atlantic salmon smolts from the Narraguagus River, Maine using ultrasonic telemetry. American Fisheries Society Symposium 69: 293-310.

Kuhn, M., and Johnson, K. 2013. Applied predictive modeling. Springer, New York.

Liaw, A., and Wiener, M. 2002. Classification and regression by randomForest. R News 2(3): 18-22.

Melnychuk, M.C., Christensen, V., and Walters, C.J. 2013. Meso-scale movement and mortality patterns of juvenile Coho salmon and steelhead trout migrating through a coastal fjord. Environ. Biol. Fishes 96(2-3): 325-339. doi:10.1007/s10641-012-9976-6.

Nelson, G.A., Chase, B.C., and Stockwell, J. 2003. Food habits of striped bass (Morone saxatilis) in the coastal waters of Massachusetts J. Northw. Atl. Fish. Sci. 32: 1-25.

Romine, J.G., Perry, R.W., Johnston, S.V., Fitzer, C.W., Pagliughi, S.W., and Blake, A.R. 2014. Identifying when tagged fishes have been consumed by piscivorous predators: application of multivariate mixture models to movement parameters of telemetered fishes. Anim. Biotelemetry 2(3). doi:10.1186/2050$3385-2-3$

Rozenstein, O., and Karnieli, A. 2011. Comparison of methods for land-use classification incorporating remote sensing and GIS inputs. Appl. Geogr. 31(2): 533-544. doi:10.1016/j.apgeog.2010.11.006.

Schultz, A., Kumagai, K., and Bridges, B. 2015. Methods to evaluate gut evacuation rates and predation using acoustic telemetry in the Tracy Fish Collection Facility primary channel. Anim. Biotelem. 3:13. doi:10.1186/s40317-015-0034-y.

Simpfendorfer, C.A., Olsen, E.M., Heupel, M.R., and Moland, E. 2012. Three-dimensional kernel utilization distributions improve estimates of space use in aquatic animals. Can. J. Fish. Aquat. Sci. 69(3): 565-572. doi:10.1139/f2011-179 
558 Thorstad, E.B., Whoriskey, F., Uglem, I., Moore, A., Rikardsen, A.H., and Finstad, B. 2012. A critical life 559 stage of the Atlantic salmon Salmo salar: behaviour and survival during the smolt and initial 560 post-smolt migration. J. Fish Biol. 81(2): 500-542. doi: 10.1111/j.1095-8649.2012.03370.x

561 Venkatesan, M., and Kulkarni, A.V.K. 2016. Comparative performance investigation of supervised and 562 unsupervised learning outlines applied in cognitive radio systems. Wireless Pers. Commun.

563 91(3): 1393-1417. doi:10.1007/s11277-016-3534-z.

564 Viera, A.J., and Garrett, J.M. 2005. Understanding interobserver agreement: the kappa statistic. Fam. 565 Med. 37(5): 360-363.

566 
567 Table 1. Summary of smolts tagged by stock and by year. Model output is based on the number of smolts 568 with detections in the study site. Model output is presented as the percent of smolts movement patterns 569 classified as Striped Bass patterns (i.e. consumed) under the binary classification criterion, as the scaled 570 estimate and estimated with $\geq 0.80$ probability of belonging to the bass movement patterns.

571 


\begin{tabular}{|c|c|c|c|c|c|c|c|c|}
\hline \multirow[t]{2}{*}{ Year } & \multirow[t]{2}{*}{$\begin{array}{l}\text { Miramichi } \\
\text { River } \\
\text { stock }\end{array}$} & \multirow[t]{2}{*}{$\begin{array}{l}\text { No. } \\
\text { released }\end{array}$} & \multirow{2}{*}{$\begin{array}{l}\text { Fork length } \\
(\mathrm{cm}) \\
\text { Mean (range) }\end{array}$} & \multirow{2}{*}{$\begin{array}{l}\text { No. smolts } \\
\text { with } \geq 1 \\
\text { detections } \\
\text { in } \\
\text { Miramichi } \\
\text { estuary }\end{array}$} & \multirow{2}{*}{$\begin{array}{l}\text { No. smolts } \\
\text { with } \geq 1 \\
\text { detections } \\
\text { at Strait of } \\
\text { Belle Isle }\end{array}$} & \multicolumn{3}{|c|}{$\begin{array}{l}\text { Inferred \% of tagged smolts } \\
\text { exhibiting Striped Bass } \\
\text { movement patterns }\end{array}$} \\
\hline & & & & & & binary & scaled & $\geq P(0.80)$ \\
\hline \multirow[t]{2}{*}{2013} & Northwest & 40 & $14.0(12.6,16.7)$ & 36 & 2 & 16.7 & 19.4 & 13.9 \\
\hline & Southwest & 65 & $14.6(13.4,16.7)$ & 41 & 5 & 17.1 & 16.5 & 14.6 \\
\hline \multirow[t]{2}{*}{2014} & Northwest & 50 & $13.6(12.1,16.7)$ & 40 & 5 & 17.5 & 19.9 & 17.5 \\
\hline & Southwest & 80 & $14.2(13.2,16.9)$ & 50 & 7 & 8.0 & 9.0 & 8.0 \\
\hline \multirow[t]{2}{*}{2015} & Northwest & 80 & $14.2(13.3,17.7)$ & 70 & 17 & 6.7 & 9.2 & 6.7 \\
\hline & Southwest & 80 & $14.2(13.0,17.0)$ & 59 & 11 & 1.9 & 2.6 & 1.9 \\
\hline \multirow[t]{2}{*}{2016} & Northwest & 60 & $14.1(12.9,18.2)$ & 50 & 8 & 18.0 & 17.6 & 16.0 \\
\hline & Southwest & 59 & $14.0(12.9,15.9)$ & 28 & 8 & 7.1 & 8.2 & 3.6 \\
\hline
\end{tabular}

572 
573 Figure 1. Map of the Miramichi River in New Brunswick, Canada. Receiver locations (black outlined

574 circles) are denoted by their respective distance $(\mathrm{km})$ up river with the zero $\mathrm{km}$ mark defined as the

575 receiver array located at Miramichi Bay mouth. Smolt release locations (black outlined star) are located

576 in both the Southwest and Northwest Miramichi Rivers. Inset map depicts the Gulf of St. Lawrence as

577 well as receiver arrays (black outlined solid line) that span the two entrances/exits of the gulf, the Strait

578 of Belle Isle (SoBI) array and the Cabot Strait (Cabot) array.

579 


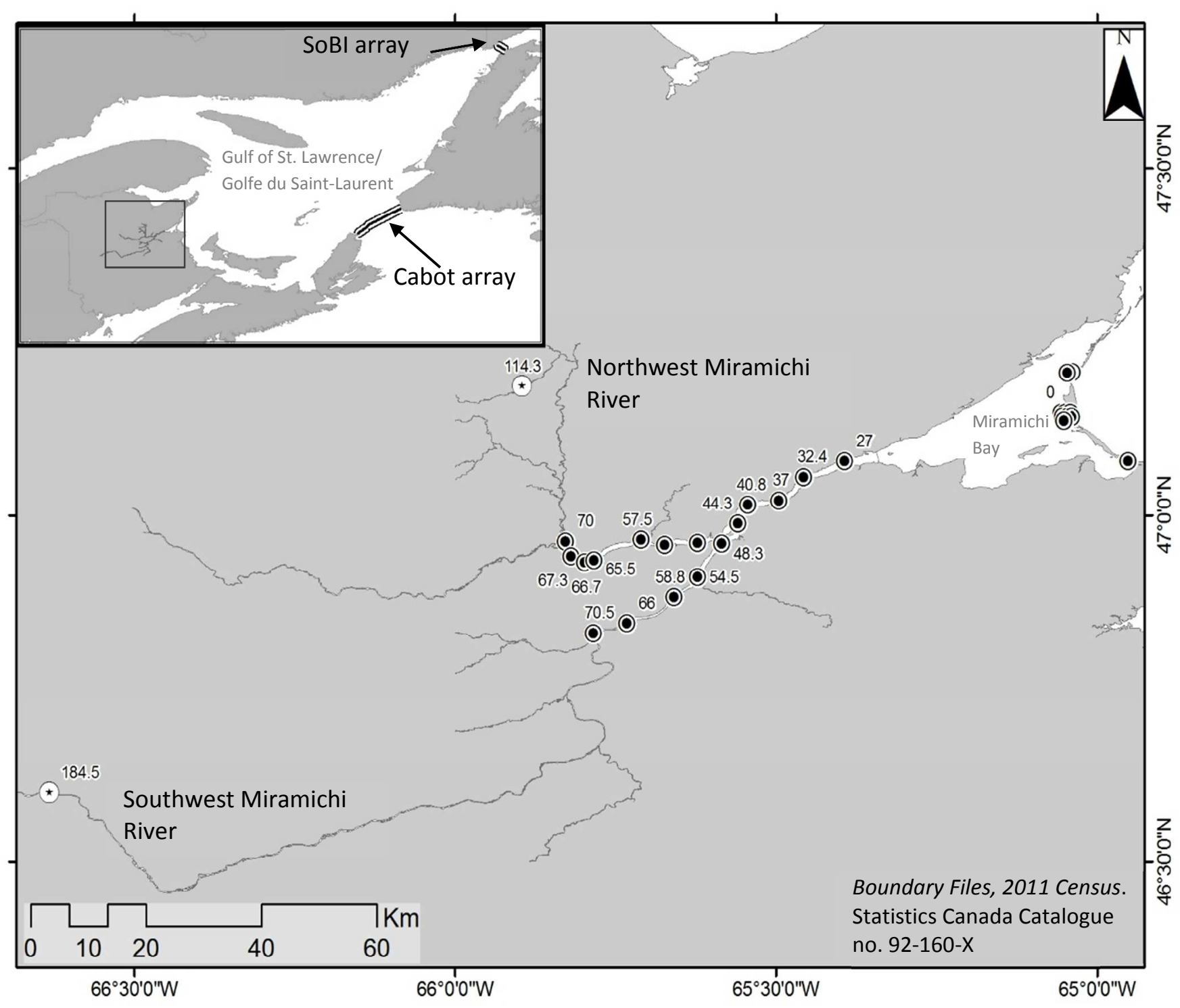


582 Figure 2. Examples of movement tracks of tagged Striped Bass and Atlantic Salmon smolts with 583 estimated probability of membership to the bass-like classification in the Miramichi estuary. Panels a 584 through d represent movement patterns of an assumed 'true' smolt given its detection at the Strait of 585 Belle Isle (SoBI). Panel b represents an individual with an 'atypical' movement track of a smolt that was 586 detected at SoBI. Panel e represents typical detection pattern of Striped Bass (assumed to represent true 587 bass movement). Panel $f$ shows a smolt movement pattern with an estimated assignment probability of 5880.99 of being a Striped Bass pattern. Under the binary classification the detection history of the 589 transmitters associated with panel $g$ and $h$ suggests membership to the smolt behaviour and bass 590 behaviour classification respectively, however there is uncertainty as to which class (smolt vs. bass) they 591 belong to. Horizontal grey shading represents the location of defined Striped Bass spawning grounds. 
a

Northwest Miramichi smolt

Bass-like movement probability $<0.01$

Detected at SoBI

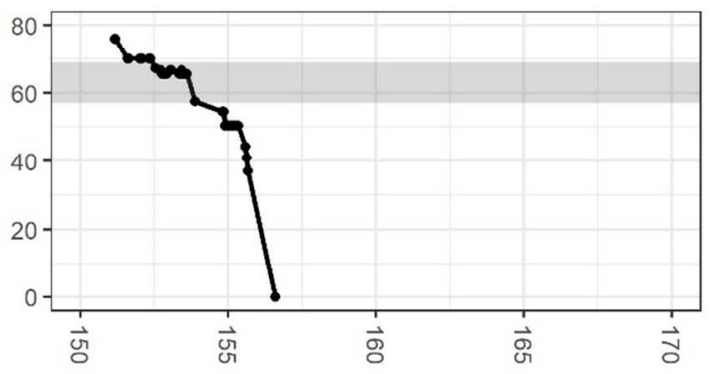

C Southwest Miramichi smolt

Bass-like movement probability $<0.01$ Detected at SoBI
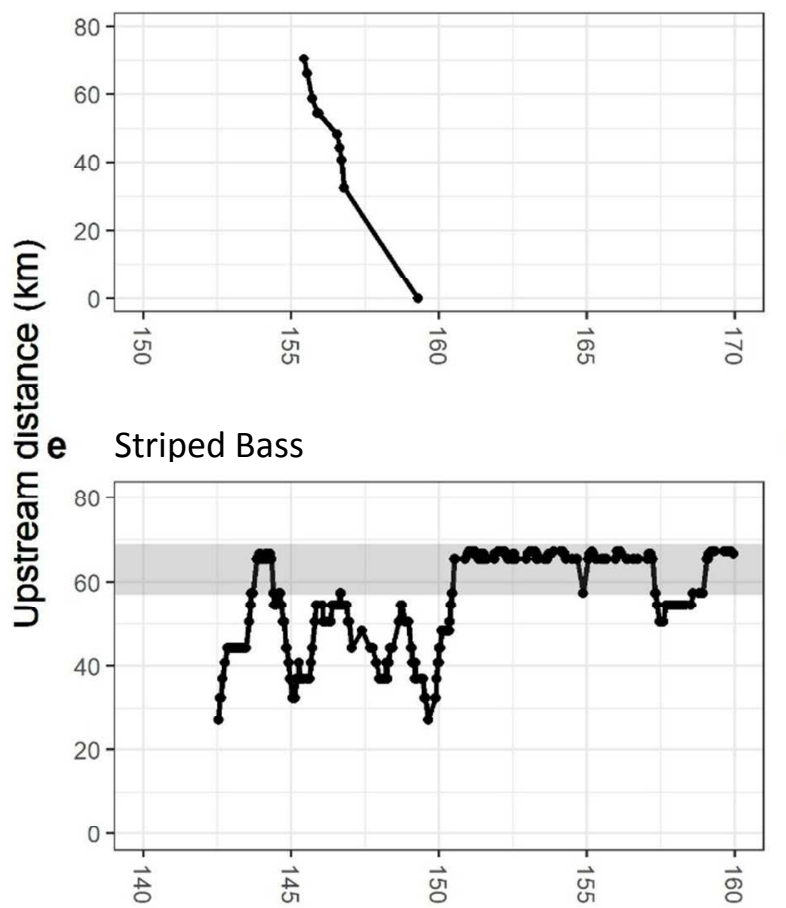

g

Northwest Miramichi smolt

Bass-like movement probability $=0.35$

Binary classification $=$ smolt-like

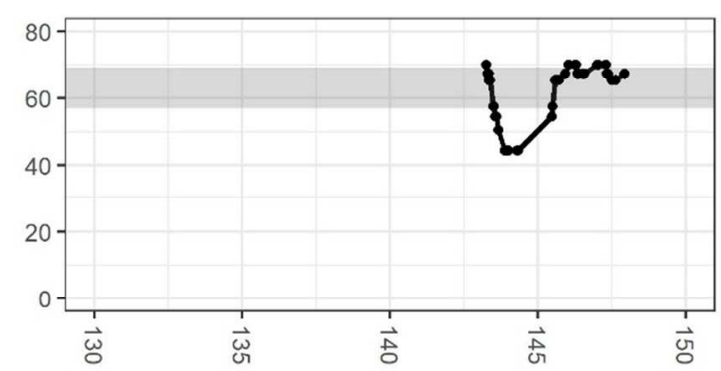

b Northwest Miramichi smolt

b Bass-like movement probability $<0.08$

Detected at SoBI

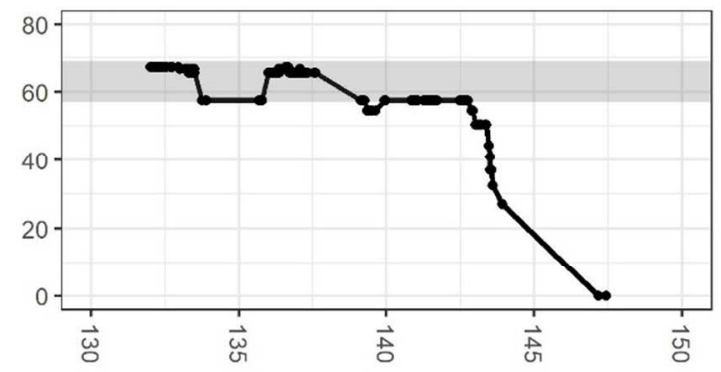

d Southwest Miramichi smolt

Bass-like movement probability $<0.01$

Detected at SoBI

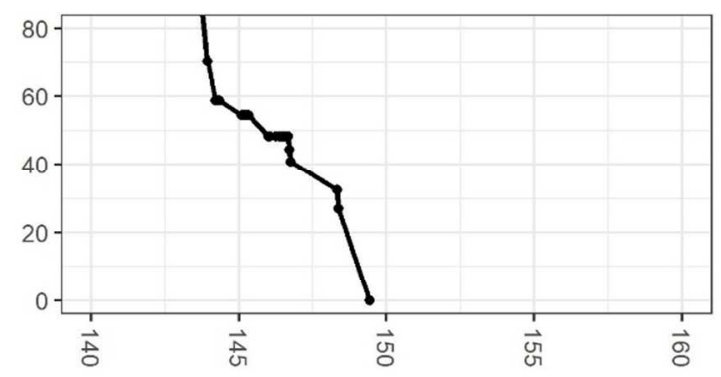

f Northwest Miramichi smolt

Bass-like movement probability $=0.99$

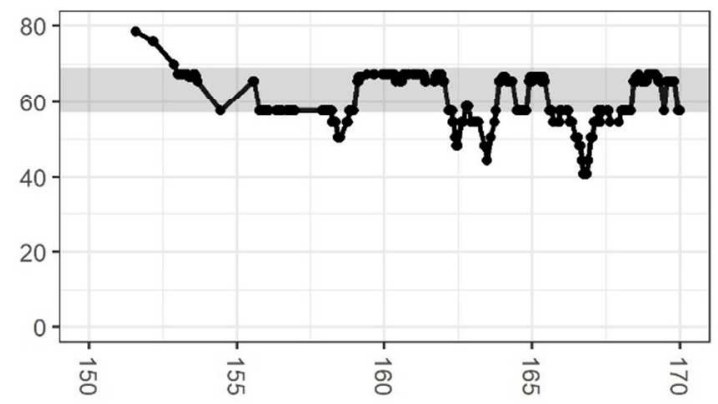

h Northwest Miramichi smolt

Bass-like movement probability $=0.73$

Binary classification $=$ bass-like

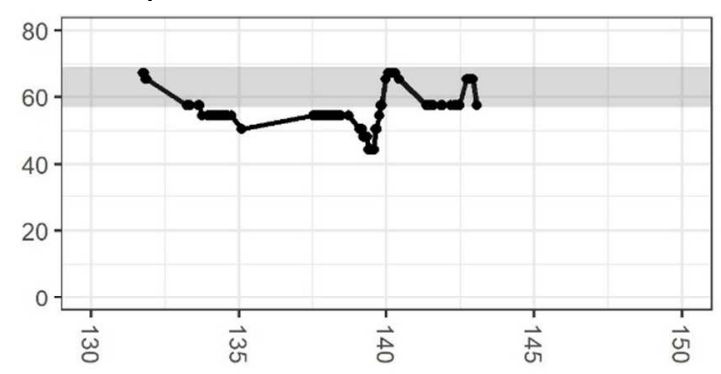

Day of year 
594 Figure 3. Bivariate plot of quantified movement characteristics. From left to right: Number of days of 595 detections (DiS), Number of days of detections in defined striped bass spawning ground (DoSG), Tally of 596 the number of upstream or downstream directional changes (NoR), The cumulative upstream distance 597 travelled in kilometers (UpStDist), Count of days between first and last detection on defined striped bass 598 spawning ground (TRoSG), The average speed $\left(\mathrm{km} \mathrm{day}^{-1}\right)$ between detections (AvgSpd), the total distance 599 travelled between detections (TotDist), and the number of visits and switches between the Northwest 600 and Southwest branches of the Miramichi River (RivSwi). Upper panel reflects relationship between 601 movement characteristics and the lower panel presents the respective correlation. Colored circles are 602 smolts (white) and Striped Bass (black) from the training data set.

603 

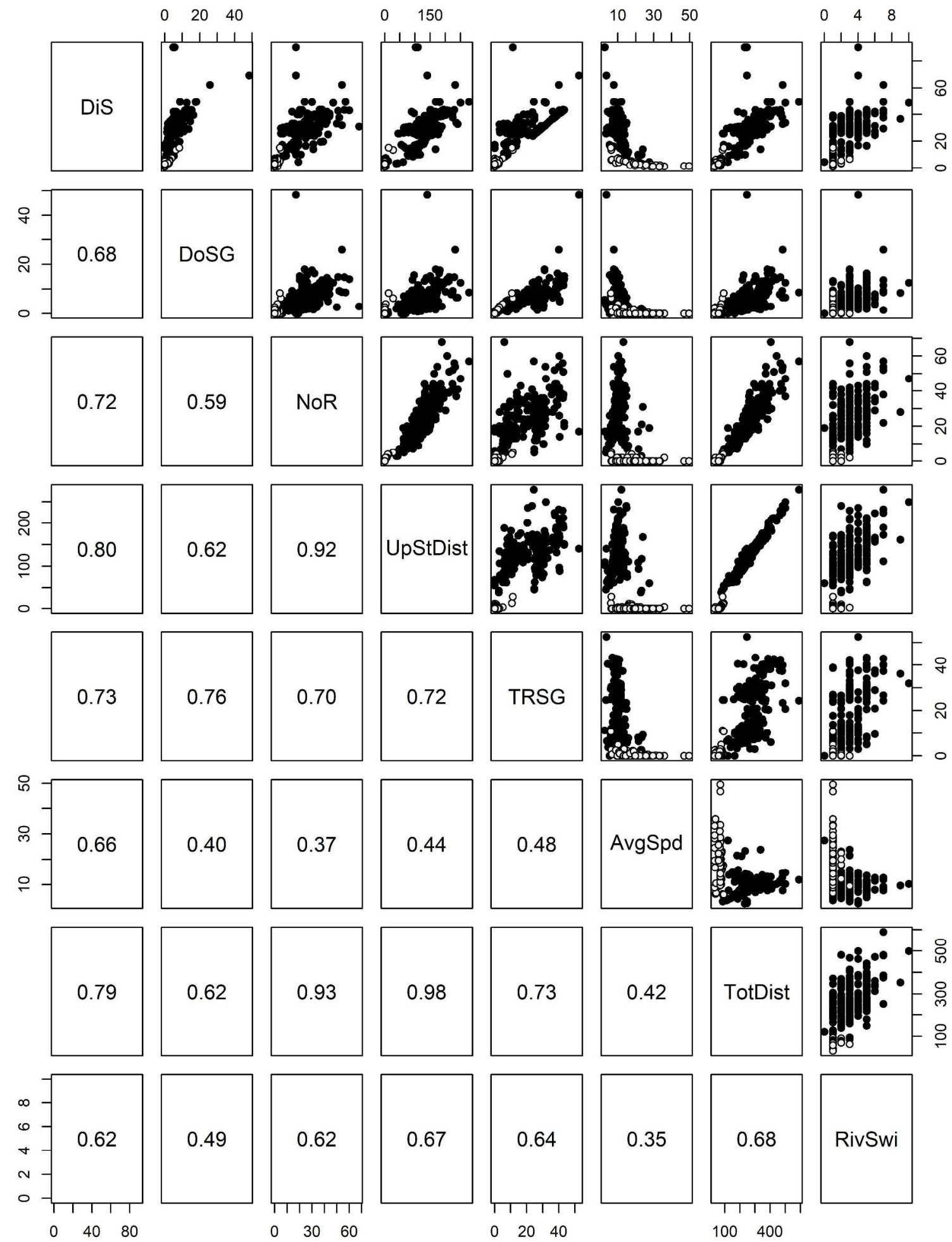
605 Figure 4. Frequency distribution of probabilities for all smolts with Striped Bass movement patterns. Each 606 bar of the histogram represents 10 percent bins, for each smolt stock tagged, between 0.00 and 1.00 607 probability of Striped Bass movement characteristics. The vertical line at 0.50 represents the cut-off point 608 at which the model separates classifications under the binary scheme. Dashed vertical lines at 0.20 and 6090.80 represent the arbitrary cut-off, with probabilities $\leq 0.2$ classified as smolt movement patterns, 610 probabilities $\geq 0.8$ classified as bass movement patterns and unknown movement patterns between 0.20 611 and 0.80 .

612

613 

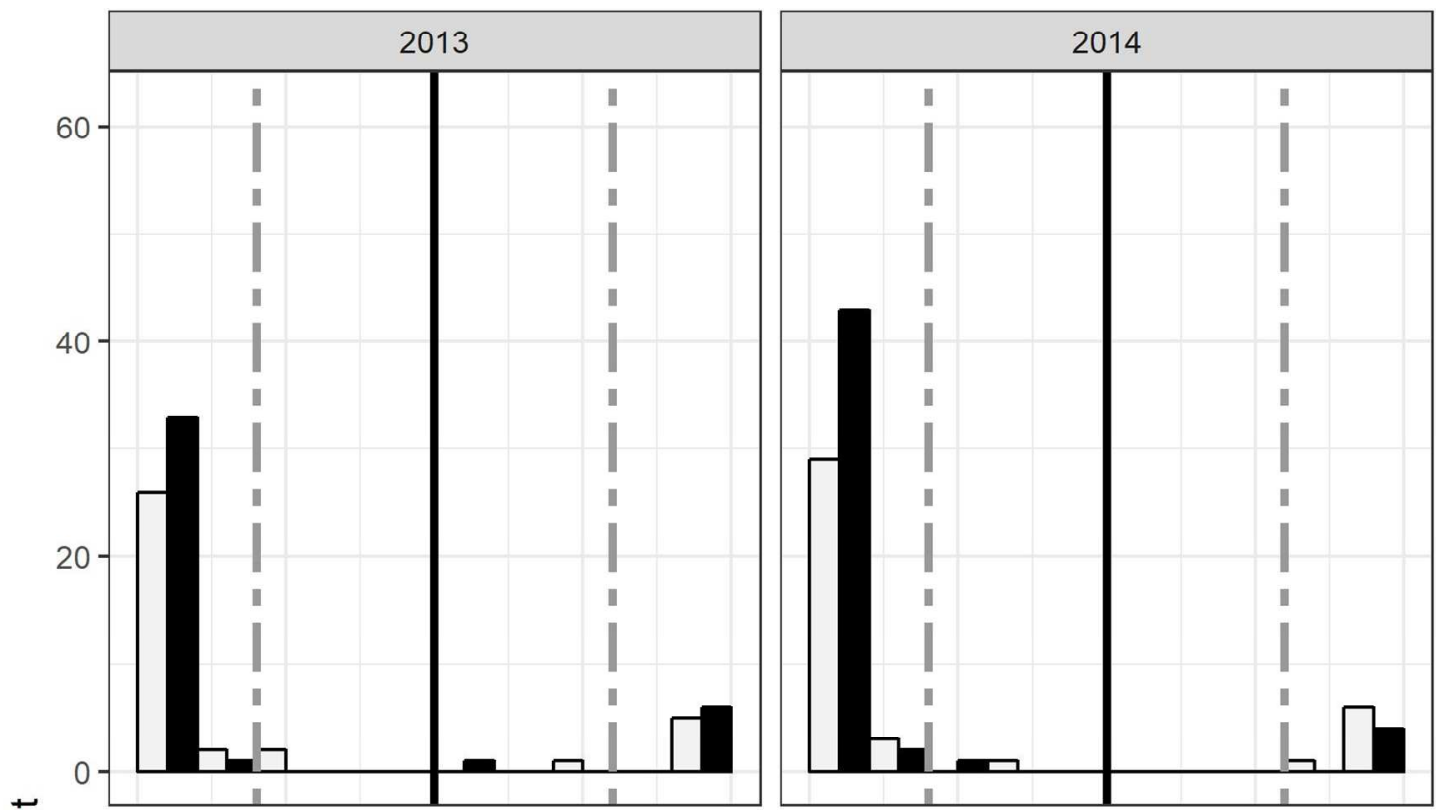

ัㅡㅇ

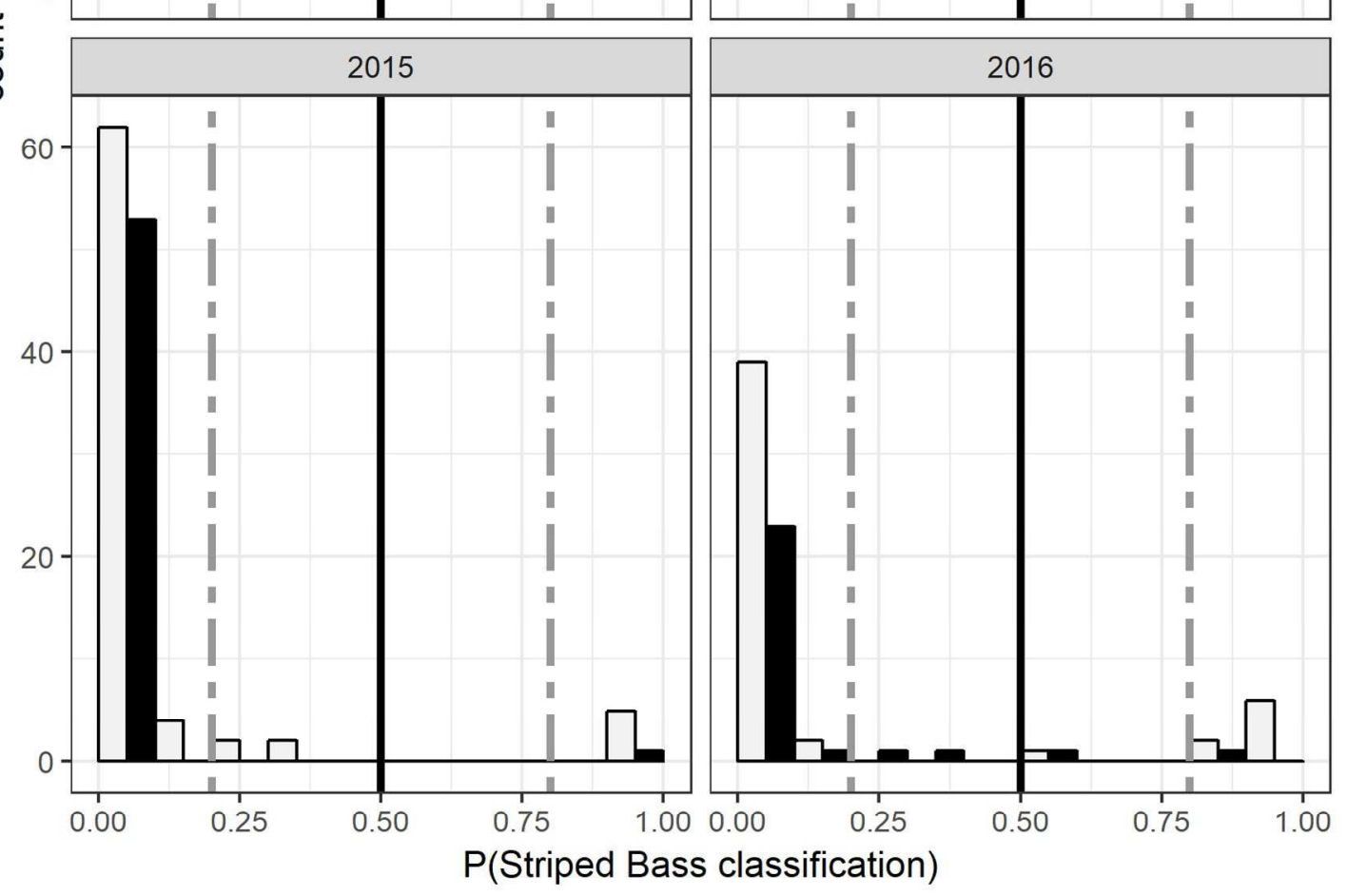

Stock

NW Miramichi SW Miramichi

614 615 
617 Figure 5. Proportion of smolt detection patterns classified as bass-like with probability $\geq 0.80$ (black) and 618 classified as unknown with probabilities $>0.20$ and $<0.80$ (grey) for each smolt stock. Corresponding 619 values are shown above each stacked bar.

620 


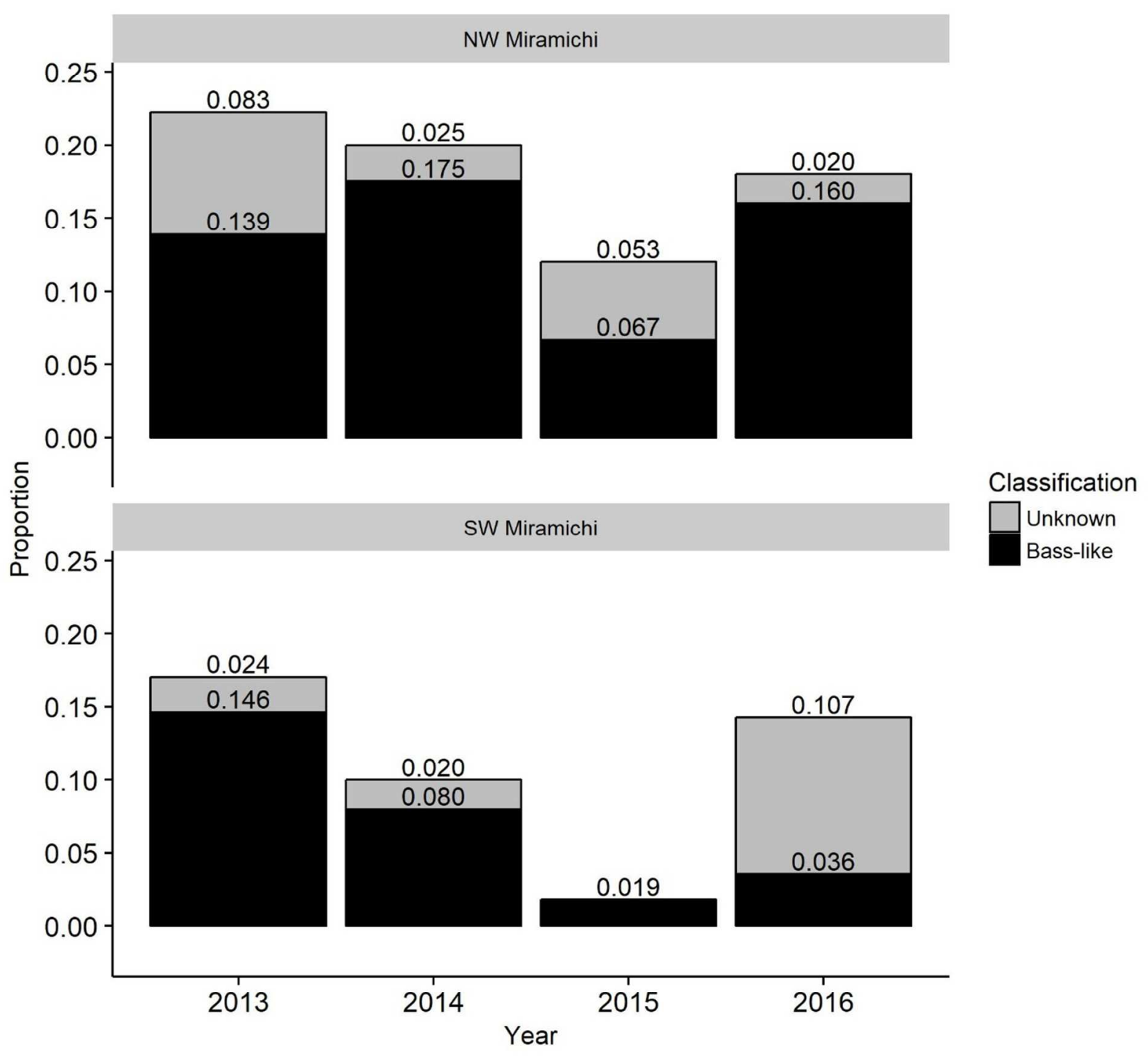


623 Figure 6. Two dimension (geographic location, date) plots and associated density isopleths of tagged

624 Striped Bass and tagged Atlantic Salmon smolts in the Miramichi estuary. Each point represents the 625 mean daily upstream position (MDUP) for each transmitter. Smolts used to calculate densities were only

626 those predicted not to have Striped Bass movement patterns under the binary classification scheme.

627 Upper panel (a) MDUP is calculated using detections on Northwest and mainstem Miramichi River

628 receivers, whereas, lower panel (b) MDUP is derived from Southwest and mainstem Miramichi River

629 receivers. Furthermore, MDUP is estimated for Striped Bass, Northwest Miramichi smolts (a) and

630 Southwest Miramichi smolts (b) by year. The horizontal line at $y=46$ represents the confluence of the

631 Northwest and Southwest Miramichi Rivers with the mainstem river. Contours for estimated 2D

632 utilization distributions via kernel density estimation overlay MDUP for each panel and sub-panel. The

633 outermost contour represents the $95^{\text {th }}$ isopleth. For each Atlantic Salmon smolt stock estimates of

634 percent of the area of the 2D density overlapping the corresponding bass $2 D$ density area is in the upper

635 right corner of each smolt stock's sub-panel. Black triangles reflect release dates of smolts for respective

636 smolt stocks and years.

637 


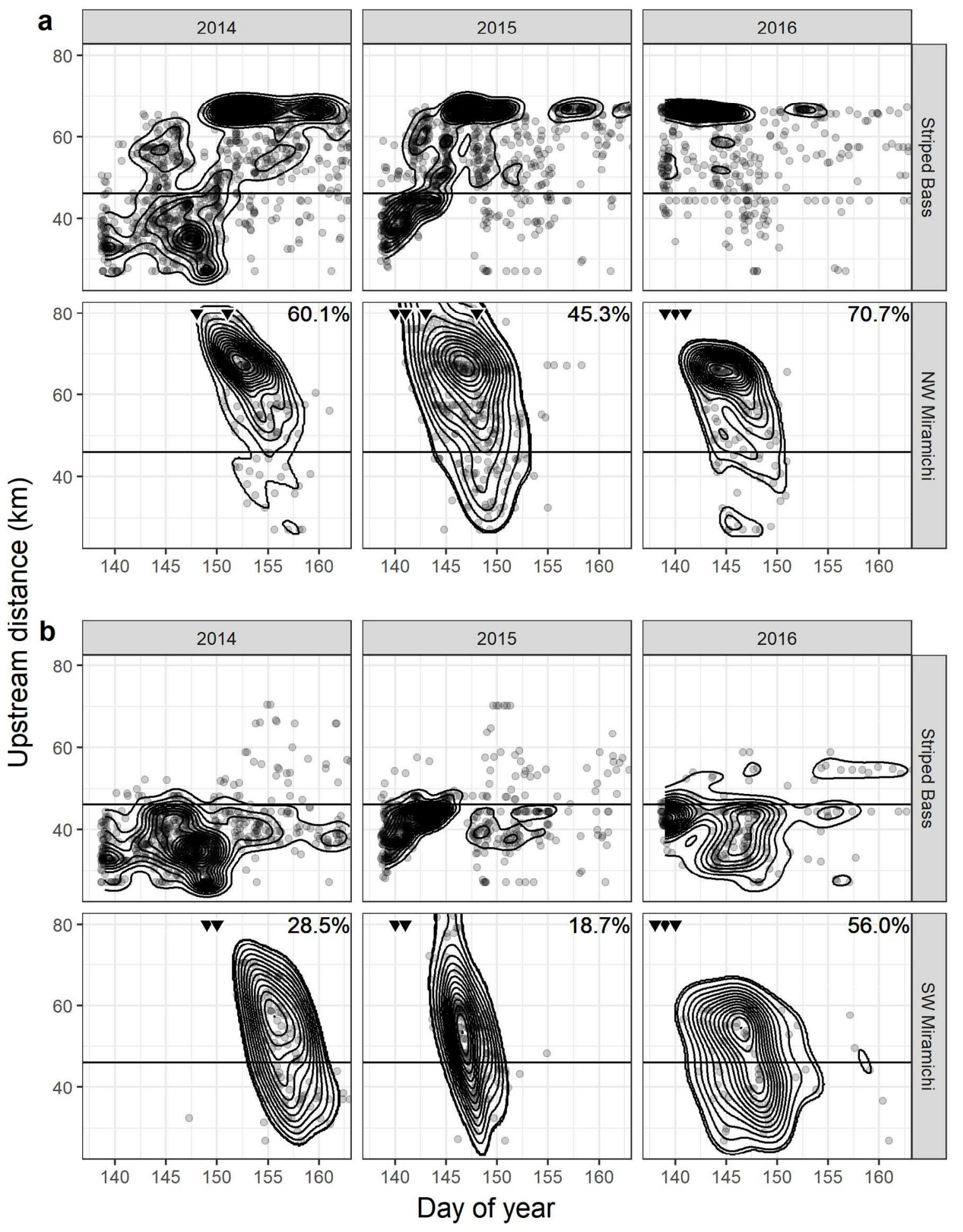

